\title{
A review of the risk factors, genetics and treatment of endometriosis in Chinese women: a comparative update
}

\author{
Yi Dai, Xiaoyan Li, Jinghua Shi and Jinhua Leng*
}

\begin{abstract}
Endometriosis is one of the major causes of economic burden and compromised quality of life in a very large percentage of Asian women. While it is perceived as a benign condition, recent research has shown that it may be a significant cause of infertility and metastatic cancer. It has also been associated with other diseases linked to the functioning of the immune system. Genetic as well as environmental factors are known to affect the manifestation and progression of endometriosis. This review aims to summarize recent research pertaining to the risk factors, diagnosis and treatment of endometriosis in Chinese women. It also provides an overview of identified genetic mutations and polymorphisms and their effects on the risk of developing endometriosis in the Chinese population. A comparison has been drawn between Asian and European-American female populations and the differences in risk factors and treatment responses have been summarized. Since traditional Chinese medicine (TCM) is often used to treat endometriosis, wherever possible, a comparison between efficacies of Western medicine and TCM in the Chinese population has also been provided. Although much progress has been made in the treatment and resolution of endometriosis, several gaps remain and this review also highlights possible areas of future research and advancement that can result in an improvement in patient outcomes and quality of life.
\end{abstract}

Keywords: Endometriosis, Chinese, Risk factors, Mutations, Treatment

\section{Plain English summary}

Endometriosis is a disorder in which the stromal or glandular tissue that normally lines the inside of the uterus grows in a location outside of the uterus. About $10-15 \%$ of women in their reproductive years are affected worldwide. Although the cause of endometriosis remains unclear, genetic and environmental factors are considered as risk factors for manifestation and progression of endometriosis. This study aims to summarize recent research pertaining to the risk factors, diagnosis and treatment of endometriosis in Chinese women. Women with endometriosis generally suffer from severe pain and other debilitating consequences which results in a compromised quality of life. Endometriosis also has a major effect on the child-bearing ability of women. Studies show that though several strategies for the management of affected patients have been developed, complete cure is not yet possible. Endometriosis treatment

\footnotetext{
* Correspondence: jinhualeng1@gmail.com

Department of Obstetrics and Gynecology, Peking Union Medical College Hospital, 1\# Shuaifuyuan, Dongcheng District, Beijing 100730, China
}

generally involves medications or surgery. Traditional Chinese medicine (TCM) that is often used for infertility treatment has shown successful results in controlling the recurrence of endometriosis following surgery thereby providing symptomatic pain relief and improving Health Related Quality of Life. Though several treatment regimens are available for the management of patients with endometrial lesions, alternative strategies are used in China. In conclusion, although Western medicine has been studied and validated more extensively for the treatment of endometriosis, both TCM and Western medicine are used equally in the treatment of endometriosis in Chinese women.

\section{Background}

Endometriosis is an estrogen-responsive, chronic condition that arises from the extra-uterine growth of the stromal or glandular tissue that lines the uterus [1]. Worldwide, it represents a significant cause of morbidity in about $10-15 \%$ of women in their reproductive years [2]. Although significant efforts have been made to 
enhance detection and subsequently treat endometriosis, diagnosis in the majority of women is delayed on average by 10 years globally [3] and by 13 years in China [4]. Identification of risk factors is integral to diagnose endometriosis. Moreover, early diagnosis is essential to effectively treat endometriosis. This review delineates the risk factors and genetic differences among Chinese women suffering from endometriosis and also updates the reader about the treatment of endometriosis in China.

\section{Endometriosis: Pathophysiology and risk factors}

The risk of endometriosis has been linked to ethnicity and several studies have reported a nine-fold increase in risk in Asian women when compared to the European-American white female population [5-7].

It is well known that endometriosis, despite having a strong genetic predisposition, is also affected by environmental exposures. Both these factors have a bearing on the difference in the risk of disease occurrence observed based on parameters such as race and ethnicity. While evidence for an association between genetic polymorphisms and risk of endometriosis is robust [8-11], evidence linking environmental factors to endometriosis risk is somewhat weaker. Environmental factors such as elevated levels of phthalate esters, persistent organochlorine pollutants, perfluorochemicals, and intra-uterine exposure to cigarette smoke among others can cause endometriosis by inducing oxidative stress, altering hormonal homeostasis, or by changing immune responses. However, further studies in different populations are required in order to measure the extent of this association [12-16]. Other risk factors, such as the presence of lower genital tract infections, have also been proposed as a possible cause of increased risk [17].

The origin and pathophysiology of endometriosis remains incompletely understood and several hypotheses that seek to explain its development and progression have been proposed (Fig. 1). The most well accepted model is that of retrograde menstruation (where endometrial cells are refluxed through the fallopian tubes and implanted onto the pelvic or peritoneal organs) accompanied by the avoidance of anoikis, wherein cells of endometrial origin able to survive outside the uterus have an imbalance between pro and anti-apoptotic factors [18, 19]. It has been reported that CD147 is one such anti-apoptotic factor and its overexpression has been shown to lead to the survival of human uterine epithelial cells outside the uterus [20]. The miRNA MiR-191 has also been shown to be involved and inhibits tumor necrosis factor- $\alpha$ induced apoptosis of ovarian endometriosis and endometrioid carcinoma cells by targeting Death-associated Protein Kinase 1 [21]. Certain molecules such as fibroblast growth factor receptor 1 have also been shown to be overexpressed in ectopic versus eutopic endometrium and in patients suffering from

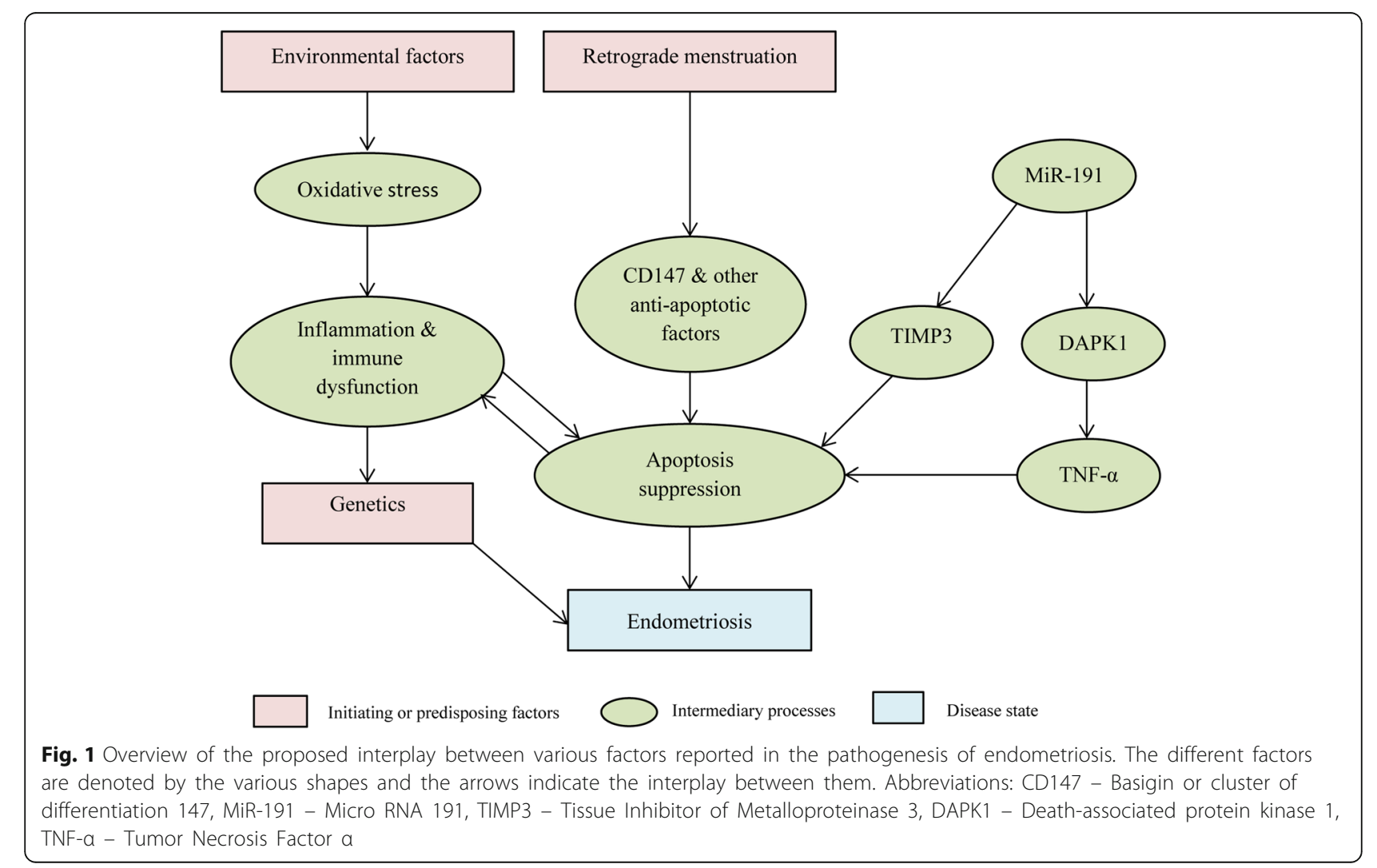


endometriosis versus healthy controls. One study also demonstrated an overexpression of fibroblast growth factor receptor 1 in patients with post-surgery recurrence [22]. In addition, studies have also revealed the involvement of miRNAs and siRNAs in disease pathology. In fact, the process of endometriosis associated ovarian cancer is thought to involve miR-191. By down-regulating and lowering protein expression of tissue inhibitor of metalloproteinases 3, which has a pro-apoptotic function, it is thought to induce the survival of ectopic endometrial cells. Interestingly, lower tissue inhibitor of metalloproteinases 3 expression has also been associated with several other types of cancer [23].

Other theories have also been put forward to explain the origin of endometriosis. Non-uterine theories propose the occurrence of coleomic metaplasia, a transdifferentiation of extrauterine tissue to ectopic endometrial tissue, probably due to endocrine disrupting chemicals or other hormonal factors [24]. A recently proposed theory suggests that bone marrow-derived stem cells can cause endometriosis. This occurs due to increased binding of the stem cell chemokine CXCR4 with its ligand CXCL12, which increases matrix metalloproteinase expression and subsequent extracellular matrix protein degradation, leading to metastasis. Furthermore, CXCR4-CXCL12 binding promotes angiogenesis through increased vascular endothelial growth factor expression [25].

Symptomatically, endometriosis is characterized by inflammation and involvement of different immune system components. Lesions may be divided into three main types, viz., peritoneal, ovarian, and deep infiltrating endometriosis, depending on their location within the body. Several pelvic and peritoneal organs may be involved, and although the involvement of the urinary tract and kidneys are rare, a single study has reported the presence of endometriosis of the renal parenchyma in a Chinese woman [26].

In general, a large degree of variation in disease severity exists amongst patients who suffer from this condition. It has also been found that an increase in the number of endometrial lesions does not always correlate with the severity of symptoms, suggesting that endometriosis is a multifaceted condition that is governed by several aspects of patient physiology. Based on global standards, disease is classified as Stage I-IV based on revised criteria pertaining to extent and severity specified by the American Society of Reproductive Medicine (rASRM), also known as the revised American Fertility Society criteria. However, this method was not robust enough to predict post-surgery pregnancy outcome [27]. To counter rASRM's shortcoming, a new staging system called the Endometriosis Fertility Index (EFI) was developed. EFI evaluated age, duration of infertility, pregnancy history, extent of endometriosis, and the least-function score to predict pregnancy outcome after surgery [28]. The Chinese Medical Association (CMA) recommends utilizing EFI to assess outcomes in endometriosis patients [29].

Women with endometriosis generally suffer from severe pain and other debilitating consequences such as dysmenorrhea, chronic pelvic pain, dyspareunia, and exgenital symptoms such as dyschezia, dysuria, hematuria, and rectal bleeding resulting in a compromised quality of life (QoL) [30, 31]. Another major effect of harboring this condition is infertility and $30-50 \%$ of the women affected by endometriosis have compromised childbearing ability [32]. A recent systematic review analyzing the outcomes of more than 1.9 million women found endometriosis to be associated with worsening of obstetric and pregnancy related outcomes such as miscarriage, pre-term labor, placenta previa, small for gestational age, and cesarean delivery as compared with healthy controls [33]. A Chinese study also reported similar results [34]. Apart from these consequences, there is also an increased risk of diseases such as cancer (especially ovarian) [35-37] and auto-immune diseases. Studies have also shown that tumors from Chinese ovarian cancer patients with pre-existing endometriosis have distinct clinico-pathological features, such as a predisposition for ovarian clear cell carcinoma, when compared to the normal Chinese population [38].

In general, the consequences of endometriosis are often under-reported and underestimated [39] and the disease represents a significant burden, both economic and qualitative [40]. Although several strategies for the management of affected patients have been developed, complete cure is not yet possible. Even after treatment with current therapeutic regimens including surgical intervention, endometriosis remains a frequently recurring disease. The following sections of this review seek to summarize the state of the art in the diagnosis and treatment of this disease, and wherever possible, to draw a comparison between strategies used in China with those deployed in the Western world for the effective resolution of disease and management of patients.

\section{Genetic basis of endometriosis in Chinese women}

Mutations and polymorphisms in several genes have been implicated in the pathophysiological process that results in endometriosis. These genes belong to diverse groups, both functionally as well as spatially. However, a strong association has been detected between single nucleotide polymorphisms (SNPs) in hormone receptor and metabolism related genes and endometriosis in Taiwanese Chinese Women [41]. A study in Taiwanese women also showed that MUC17 polymorphisms are involved in endometriosis development and associated infertility [11]. In addition, by comparing the mutational landscape between normal women and Chinese 
endometriosis patients, a recent whole exome sequencing study implicated genes involved in biological adhesion, cell-cell junctions, and chromatin-remodeling complexes in the development of endometriosis [42].

Much research based on genetic factors that influence endometriosis has focused on Han Chinese women, since a relatively higher rate of disease prevalence has been detected in this population. In addition, genome wide association studies found that polymorphisms in rs12700667 located within the intergenic region of 7p15. 2 are also associated with an elevated risk of ovarian endometriosis in North Chinese women [43]. Although several studies have detected differences in genetic mutations that predispose Asian and Western populations to endometriosis, a recent genome wide association meta-analysis revealed a significant overlap in loci linked with endometriosis risk in Japanese and European populations [44].

Mutation association studies conducted in different populations in order to link genetic mutations to risk of endometriosis presents a very strong body of evidence supported by a large number of meta-analyses. Some of these associations related to Chinese and Asian populations have been summarized in Table 1 .

\section{Current techniques for diagnosis and biomarkers of endometriosis}

Imaging techniques such as color Doppler ultrasounds and CT/ MRI scans are recommended for the initial diagnosis of endometriosis by the CMA, although MRI primarily visualizes ovarian and not peritoneal endometriosis [39]. However, due to the necessity for a histological verification of the presence of endometrial glands/stroma combined with a laparoscopy (which is regarded as the current gold standard for the confirmation of the presence of endometrial lesions) and also due to several cases of misdiagnosis, an accurate identification of endometriosis occurs after an average of 6 years following initial onset [29, 45]. In conjunction with a laparoscopic diagnosis of endometriosis, a scoring system is generally used for the assessment of severity of disease. The most commonly used one is the revised American Fertility Society scoring system for the extent and severity of ectopic endometrial adhesions. The CMA guidelines also use the Endometriosis Fertility Index (EFI) scoring system in order to assess patient fertility related parameters.

The technique of laparoscopy, however, has several drawbacks of which its invasive nature and reliance on the skill of the surgeon for an accurate visual inspection of the pelvic cavity representing the major issues. In addition, it is not always capable of detecting deep infiltrating lesions, resulting in several undiagnosed cases. However, efforts are being made in order to devise non-invasive methods for the diagnosis of endometriosis and certain studies have demonstrated an association between elevated serum levels of CA125 in endometriosis patients, suggesting that they may be used as biomarkers during the diagnostic process in both, Asian as well as European-American populations [46]. Another study has also demonstrated the superiority of CA125 over the platelet-lymphocyte ratio in the diagnosis of moderate to severe endometriosis in Chinese women [47]. However, CA125 levels cannot be used as a diagnostic biomarker in isolation due to a low sensitivity and specificity for endometrial lesions. One of the major concerns of the use of CA-125 as a biomarker is that elevated serum levels have been detected in other gynecological pathologies as well. However, CMA guidelines indicate that CA-125 elevation may be useful for the detection of advanced stage endometriosis, endometriosis combined with adenomyosis or obvious pelvic inflammation, and also in the diagnosis of endometrioma rupture $[48,49]$.

Several other strategies are being developed and panels that detect levels of inflammatory and non-inflammatory markers are still not very specific for endometrial lesions $[50,51]$. Amongst inflammatory markers a systematic review identified IL- 8 as the best studied, with MCP-1 and CCL5 coming a close second [50]. Another strategy for non-invasive diagnosis of disease is the use of miRNA panels. A prospective study has also shown that the urine of affected patients had a distinct peptide pattern that can be developed into an assay for diagnosis [52].

Despite these advances, recent Cochrane reviews have concluded that none of the currently available techniques, whether lab-developed or already existing commercial platforms, are suitable for use as a replacement for laparoscopy or even as a diagnostic triage test $[53,54]$. Thus, more emphasis on targeting endometriosis-specific markers for diagnostic purposes is required in order to develop a non-invasive diagnostic testing platform for accurate and non-invasive identification of disease.

\section{Current strategies for the management of endometriosis in China and worldwide}

Since endometriosis is associated with debilitating pain and a very high risk of infertility, most treatments aim to alleviate symptoms of the disease such as dysmenorrhea and dyspareunia while simultaneously improving pregnancy and fertility outcomes. Thus, the use of combinatorial regimens is common, and often, surgical excision or ablation of lesions using laparoscopy is often done in order to reduce large ectopic endometrial masses. However, based on recommendations by international guidelines, decisions regarding the timing and aptness of surgical intervention are generally guided by patient preferences, disease severity and fertility goals. Surgical removal is generally followed by GnRHa or oral contraceptives in order to prevent disease recurrence and to provide symptomatic relief. Clinical guidelines published by the Obstetrics and Gynecology 
Table 1 Genetic Mutations and Polymorphisms and their impact on the risk of Endometriosis and Infertility in Chinese women

\begin{tabular}{|c|c|c|c|c|c|}
\hline Gene/ Protein Name & Protein Function & $\begin{array}{l}\text { Mutation/ } \\
\text { Polymorphism }\end{array}$ & Risk of Endometriosis/Infertility & Population & References \\
\hline \multirow{3}{*}{$\begin{array}{l}\text { ESR } 1 \text { Estrogen receptor } \\
\text { alpha }\end{array}$} & \multirow[t]{3}{*}{ Hormone Receptor } & (TA)n Short & Increased/Un-reported & Mixed & Wang et al., 2013 [86] \\
\hline & & (TA)n Long & Decreased/Unreported & Mixed & Wang et al., 2013 [86] \\
\hline & & rs3798573 A/G & Increased/Increased & Han Chinese & Wang et al., 2013 [86] \\
\hline $\begin{array}{l}\text { ESR } 2 \text { Estrogen receptor } \\
\text { beta }\end{array}$ & Hormone Receptor & $\begin{array}{l}\text { rs } 4986938 \text { and } \\
\text { rs } 1256049 \\
\text { polymorphisms }\end{array}$ & $\begin{array}{l}\text { No significant association detected/ } \\
\text { Unreported }\end{array}$ & $\begin{array}{l}\text { Asian and } \\
\text { European- } \\
\text { American }\end{array}$ & Guo et al., 2014 [87] \\
\hline PR Progesterone Receptor & Hormone Receptor & rs104283 CT SNP & Increased/Un-reported & $\begin{array}{l}\text { Southern Han } \\
\text { Chinese }\end{array}$ & Mao et al., 2015 [88] \\
\hline $\begin{array}{l}\text { GST Glutathione-S- } \\
\text { transferases M1/T1 }\end{array}$ & Metabolic Enzyme & Null genotype & Increased/ Unreported & Chinese & $\begin{array}{l}\text { Chen et al., } 2015 \text { [9]; } \\
\text { Zhu et al., } 2014 \text { [89] }\end{array}$ \\
\hline $\begin{array}{l}\text { GALT Galactose-1- } \\
\text { phosphate uridyl transferase }\end{array}$ & Metabolic Enzyme & Q188R and N314D & $\begin{array}{l}\text { No significant association detected/ } \\
\text { Unreported }\end{array}$ & Chinese & He et al., 2006 [90] \\
\hline $\begin{array}{l}\text { BDNF Human brain-derived } \\
\text { neurotrophic factor }\end{array}$ & Tropic factor & $\begin{array}{l}\text { Val66Met } \\
\text { polymorphism }\end{array}$ & Increased/Increased & Han Chinese & Zhang et al.,2012 [91] \\
\hline $\begin{array}{l}\text { FGF2 Fibroblast Growth } \\
\text { Factor } 2\end{array}$ & Growth factor & 754C/G polymorphism & Increased/Un-reported & North Chinese & Kang et al., 2012 [92] \\
\hline \multirow[t]{3}{*}{$\begin{array}{l}\text { VEGF Vascular endothelial } \\
\text { growth factor }\end{array}$} & \multirow[t]{3}{*}{ Growth factor } & $+405 G>C$ & $\begin{array}{l}\text { No significant association detected/ } \\
\text { Unreported }\end{array}$ & $\begin{array}{l}\text { Asian and } \\
\text { European- } \\
\text { American }\end{array}$ & Fang et al., 2015 [93] \\
\hline & & $-1154 A$ & Decreased/Unreported & North Chinese & Liu et al., 2009 [94] \\
\hline & & $-2578 \mathrm{~A}$ & Decreased/Unreported & North Chinese & Liu et al., 2009 [94] \\
\hline \multirow{2}{*}{$\begin{array}{l}\text { VEGFR-2 Vascular } \\
\text { endothelial growth factor } \\
\text { receptor 2) }\end{array}$} & \multirow{2}{*}{$\begin{array}{l}\text { Growth factor } \\
\text { receptor }\end{array}$} & $1192 C / T+T / T$ & Decreased & \multirow[t]{2}{*}{ Han Chinese } & \multirow[t]{2}{*}{ Kang et al., 2013 [95] } \\
\hline & & $1192 C / C$ & Increased & & \\
\hline TP53 & \multirow[t]{3}{*}{ Tumor suppressor } & $\begin{array}{l}\text { codon } 72 \\
\text { polymorphism Pro/Pro } \\
\text { and Arg/Pro }\end{array}$ & Increased & $\begin{array}{l}\text { Chinese and } \\
\text { Asian }\end{array}$ & $\begin{array}{l}\text { Chang et al., } 2002 \\
\text { [96]; Jia et al., } 2012 \\
\text { [97] }\end{array}$ \\
\hline $\begin{array}{l}\text { MMP-2 Matrix } \\
\text { metalloproteinase-2 }\end{array}$ & & $\begin{array}{l}1306 C->T \text { and }-735 C- \\
>T\end{array}$ & Increased/Unreported & North Chinese & Kang et al., 2008 [98] \\
\hline $\begin{array}{l}\text { TIMP-2 Tissue inhibitor of } \\
\text { metalloproteinase-2 }\end{array}$ & & $418 \mathrm{G}->\mathrm{C}$ & Decreased/Unreported & North Chinese & Kang et al., 2008 [98] \\
\hline E-Cadherin & $\begin{array}{l}\text { Cell Adhesion } \\
\text { Molecule }\end{array}$ & rs8049282 SNP & Increased/Increased & $\begin{array}{l}\text { Northern } \\
\text { Chinese }\end{array}$ & Kang et al., 2014 [99] \\
\hline COX-2 Cyclo-oxygenase 2 & $\begin{array}{l}\text { Inflammatory } \\
\text { pathway Enzyme }\end{array}$ & $\begin{array}{l}\mathrm{G} \text { to } \mathrm{A} \text { at }-1195 \\
\text { (promoter) }\end{array}$ & Increased/ Unreported & Chinese & $\begin{array}{l}\text { Wang et al., } 2015 \\
{[100]}\end{array}$ \\
\hline $\begin{array}{l}\text { ICAM-1 Intercellular } \\
\text { Adhesion Molecule } 1\end{array}$ & $\begin{array}{l}\text { Cell Adhesion } \\
\text { Molecule }\end{array}$ & K469E polymorphism & $\begin{array}{l}\text { Further decreased in Asian populations } \\
\text { compared to European-Americans/ } \\
\text { Unreported }\end{array}$ & $\begin{array}{l}\text { Asian and } \\
\text { European- } \\
\text { American }\end{array}$ & $\begin{array}{l}\text { Pabalan et al., } 2015 \\
\text { [101] }\end{array}$ \\
\hline CYP19 & \multirow[t]{2}{*}{$\begin{array}{l}\text { Aromatase } \\
\text { Enzyme }\end{array}$} & rs700518AA & $\begin{array}{l}\text { No significant association detected/ } \\
\text { Increased upon pre-existing endometriosis }\end{array}$ & Chinese & $\begin{array}{l}\text { Wang et al., } 2014 \\
\text { [102] }\end{array}$ \\
\hline FCRL3 & & rs7528684 & $\begin{array}{l}\text { Unreported/ Increased upon pre-existing } \\
\text { endometriosis }\end{array}$ & Han Chinese & $\begin{array}{l}\text { Zhang et al., } 2015 \\
\text { [103] }\end{array}$ \\
\hline IL-16 Interleukin 16 & Cytokine & $\begin{array}{l}\text { rs } 4778889 \mathrm{~T} / \mathrm{C} \\
\text { polymorphism }\end{array}$ & Increased/ Unreported & Chinese & Gan et al., 2010 [104] \\
\hline $\begin{array}{l}\text { FSHR Follicle Stimulating } \\
\text { Hormone Receptor }\end{array}$ & Hormone receptor & $\begin{array}{l}\text { SNP: } 680 \text { Ser/Ser and } \\
\text { 680Ser/Asn }\end{array}$ & Decreased/Unreported & $\begin{array}{l}\text { Taiwanese } \\
\text { Chinese }\end{array}$ & $\begin{array}{l}\text { Wang et al., } 2011 \\
\text { [105] }\end{array}$ \\
\hline \multirow{3}{*}{$\begin{array}{l}\text { XRCC4 } X \text {-ray repair cross- } \\
\text { complementing group } 4\end{array}$} & \multirow[t]{3}{*}{ DNA repair gene } & codon $247^{*} \mathrm{~A}$ & Increased/Unreported & \multirow{3}{*}{$\begin{array}{l}\text { Taiwanese } \\
\text { Chinese }\end{array}$} & \multirow{3}{*}{$\begin{array}{l}\text { Hsieh et al.,2008 } \\
{[106]}\end{array}$} \\
\hline & & promoter-1394*T & Increased/Unreported & & \\
\hline & & $\begin{array}{l}\text { Intron } 3 \text { I/D } \\
\text { polymorphism }\end{array}$ & $\begin{array}{l}\text { No significant association detected/ } \\
\text { Unreported }\end{array}$ & & \\
\hline \multirow[t]{3}{*}{ FOXP3 } & \multirow{3}{*}{$\begin{array}{l}\text { Transcription } \\
\text { factor }\end{array}$} & rs2280883 & \multirow{3}{*}{$\begin{array}{l}\text { No significant association detected/ } \\
\text { Unreported }\end{array}$} & \multirow[t]{3}{*}{ Han Chinese } & \multirow[t]{3}{*}{ Wu et al., 2013 [107] } \\
\hline & & rs3761548 & & & \\
\hline & & rs3761549 & & & \\
\hline
\end{tabular}




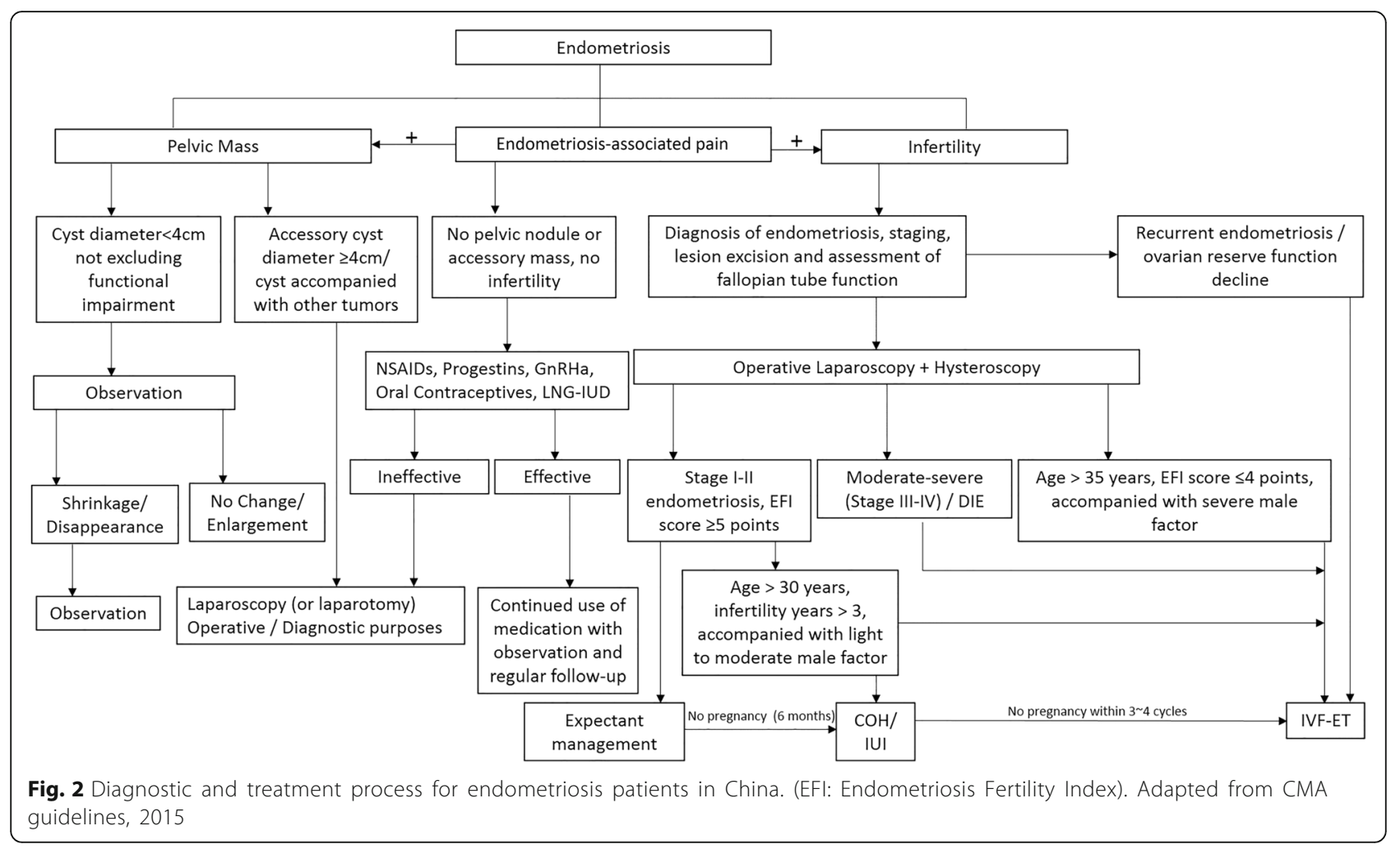

branch of the CMA recommend specific treatment strategies based on presenting symptoms (i.e., only pain or pain with infertility) [29]. A flowchart outlining the diagnostic and treatment process for these two different types of patient populations in China are shown in Fig. 2 [29].

The following sub-sections of this review focus on the different types of treatment recommended for endometriosis and their advantages and drawbacks.

\section{Surgical treatment}

The goal of surgical treatment for endometriosis is to enable lesion resection, alleviate symptoms and improve fertility outcomes while simultaneously preserving internal anatomy. The decision of which type of surgery to undertake depends on the extent of endometriosis related pain and the fertility goals of the patient. Different types of surgical interventions can be used for the treatment of endometrial pain. However, such treatment is only recommended after the diagnosis of endometriosis has been histologically confirmed (after performing a laparoscopic examination).

A large body of clinical evidence supports the use of surgical laparoscopy to remove extraneous endometrial lesions. While guidelines recommend the use of ablation and surgical excision for the treatment of endometrial pain, such treatment is not recommended for advanced forms of the disease. Clinical guidelines also separate the type of surgical treatment to be used depending on whether ovarian endometriosis is detected. In general, the European Society of Human Reproduction and Embryology (ESHRE) guidelines recommend the use of cystectomy over drainage and coagulation and $\mathrm{CO}_{2}$ ablation in women with ovarian endometrioma [55]. The CMA specifically recommends laparoscopic surgery for cases in which endometriosis is accompanied by infertility and where large ovarian cysts (> $4 \mathrm{~cm}$ ) are detected. In case of deep endometrial lesions, the CMA as well as ESHRE guidelines recommend surgical resection, with a caveat on the high complication rates arising from such treatment. In women who do not have fertility goals and fail to respond to conservative treatments, a hysterectomy is recommended by both sets of guidelines. In addition, surgical resection of nerve pathways by pre-sacral neurectomy is only recommended as an add on to conservative treatment, although this requires a very high degree of skill $[29,55]$.

\section{Medical treatment}

Several types of therapies have been recommended for the treatment of endometriosis by different clinical guidelines (depending on the presenting symptoms of the patient and the nature and extent of lesions), such as Non-Steroidal Anti-Inflammatory Drugs, oral contraceptives, progestins and $\mathrm{GnRH}$-agonists. Guidelines also recommend the empirical treatment of endometriosis based on presenting symptoms only, without the need for a laparoscopic confirmation of diagnosis. In this regard, both the ESHRE and rASRM guidelines do not distinguish between first and second line 
treatment and recommend the use of NSAIDS, progestins (such as dienogest and danzol), oral contraceptives and GnRH agonists. The World Endometriosis Society (WES) guidelines recommend the use of NSAIDs, continuous oral contraceptives and progestins as first line treatment while $\mathrm{GnRH}$ agonists and the levonorgestrel intrauterine system (LNG-IUS) system are recommended as second line treatment. CMA guidelines indicate the use of empirical treatment in those cases where there is no obvious pelvic mass or infertility and first and second line treatment in these cases is aligned with the recommendations by the WES. The use of second line treatment is recommended after first line treatment has proved ineffective. In addition, the CMA recommends that surgery should be considered when second line treatment also fails. Effectiveness of each line of treatment can be checked using standard diagnostic procedures mentioned earlier.

While the treatment duration of NSAIDS has not been explicitly mentioned, the CMA recommends using oral contraceptives for 6 months or longer, progestins for 6 months, and GnRH agonists for 3 to 6 months or longer [29]. However, both the ESHRE and CMA recommend the continuous use of hormonal treatment post-surgery for the prevention of recurrence and previous studies have also shown that the discontinuation of hormonal therapy post-surgery leads to a higher rate of recurrence [56]. Specifically, the rASRM recommends the use of aromatase inhibitors, danazol, the LNG-IUS and medroxyprogesterone acetate as post-operative medical treatment. After a laparoscopic confirmation has been established, NSAIDs are recommended as the first line of treatment if lesions are minor and not of the deep infiltrating type.

In case of major symptoms and large, deep infiltrating lesions, hormonal therapy is recommended for use in combination with surgical excision by both, the CMA and ESHRE guidelines $[29,45]$. Hormonal therapy may be divided into two categories, based on molecular targets. Broadly, they are classified as those that affect estrogen metabolism and responsiveness and those that affect progesterone responsiveness. A recent systematic review and metaanalysis conducted to assess the efficacy of the use of oral contraceptives after surgical excision of endometrial lesions concluded that combinatorial treatment is more effective in preventing recurrence than surgery alone. However, from their analysis the authors reported that this advantage did not extend to the improvement of pregnancy outcomes [57]. In a randomized, post-laparoscopic study of 280 Chinese women with ovarian endometriosis, the authors compared side effects and menopausal symptoms of leuprorelin and triptorelin (both $\mathrm{GnRH}$ antagonists) treatment. They reported that leuprorelin was milder than triptorelin, with a gradual reduction in hormone levels and fewer menopausal symptoms [58]. In another study of Chinese endometriosis patients that evaluated the timing of $\mathrm{GnRH}$ agonist administration (goserelin, $3.6 \mathrm{mg}$ either $3-5$ days postoperatively or on days $1-5$ of menstruation) the authors reported that although the efficacy of treatment was equal in women with stage III-IV endometriosis, uterine bleeding over the course of the 28 day menstrual cycle was reduced in the former group [59]. A new crosslinked hyaluronan gel was also evaluated for its ability to reduce postoperative adhesions in a randomized study comprising of 215 Chinese women who underwent surgical laparoscopy for the initial removal of existing endometrial lesions. The study found that use of the gel decreased the number and severity of post-operative adnexal and abdominopelvic adhesions in patients, thus potentially reducing the incidence of disease recurrence [60]. In this study, the authors propose that since hyaluron has a sufficiently long elimination half -life (metabolic clearance is slowed down by its ability to crosslink), it is able to persist within the body for the time window during which new adhesions are formed.

Since genetic factors linked to ethnicity are known to affect the risk of developing endometriosis, studies have attempted to address the question of whether genetic differences extend to differences in responses to treatment. One such meta-analysis evaluated responses to $\mathrm{GnRH}$ agonists and to the progestin dienogest in European versus Japanese populations. Although the authors reported no differences in response rates or HRQoL parameters in either population and found both lines of treatment equally efficacious, dienogest treatment was found to be superior in terms of bone mineral density in both populations [61]. Some clinical evidence for genetically influenced racial disparity in endometrial cancer comes from a retrospective study which reported that African-American women experienced lower recurrence-free survival after using estrogen replacement therapy, possibly due to differences in estrogen metabolism [62]. However, further studies are required to understand the clinical implications of recently discovered racial differences, such as in microRNAs [63] and oncogene mutations [64].

Several alternative strategies have been used in order to improve the quality of life in women undergoing hormonal treatment for endometriosis and to reduce side effects of the therapy itself. For example, techniques such as progressive muscular relaxation training have been used effectively in order to reduce anxiety and depression in Chinese Han women receiving GnRH treatment for endometriosis [65].

In general, guidelines by the CMA, ESHRE and the rASRM encourage treatment strategies which aim to reduce and eliminate pain, recurrence and the use of multiple surgeries.

\section{Traditional Chinese medicine (TCM)}

TCM is used in Chinese patients to control the recurrence of endometriosis following surgery, provide 
symptomatic pain relief, and improve Health Related Quality of Life (HRQoL). It is also often used to treat infertility. Some low-quality evidence from a Cochrane review showed Chinese herbal medicine to be superior to danazol treatment for the alleviation of symptoms such as pain and dysmenorrhea [66]. TCM users were also less likely to require surgical treatment for endometriosis than non-users [67]. Moreover, TCM was as effective as Western medicine (WM) in controlling the recurrence of pelvic endometriosis and improving fertility outcomes after conservative surgery [68], but better than WM at improving HRQoL [69]. On the other hand, a single randomized control trial demonstrated that TCM, and oral contraceptives in combination with laparoscopy were both non-superior to laparoscopy alone in the treatment of endometriosis [70]. Additionally, the underlying mechanisms of TCM remain unstudied. Furthermore, a major gap in knowledge is represented by the fact that Chinese medicine has never been compared with a placebo in the treatment of endometriosis symptoms, and hence, further research is required in order to confirm its effectiveness [66]. Thus, although Chinese medicine is often used for the management of endometriosis patients, there is a lack of high quality clinical evidence that supports its effectiveness in comparison with other mainstream treatment strategies.

Due to the absence of rigorous clinical evidence that supports the use of Traditional Chinese medicine for the treatment of endometriosis, the Delphi process (which is used in order to synthesize expert opinion for alternative medical interventions) was used in order to develop guidelines that govern the use of Chinese herbal medicine in the management of endometriosis patients [71]. This guideline informs practitioners about the different Chinese herbs that are used most commonly for the treatment of specific symptoms and outlines different patient management strategies based on an initial assessment of traditional Chinese physiology and pathology.

Thus, although several treatments exist for the management of patients with endometrial lesions, alternative strategies are commonly used in China. Since such strategies have not been adequately evaluated, further research that addresses this issue is required in order to improve patient outcomes, both in terms of fertility as well as quality of life.

\section{Treatment of infertility}

Since approximately $30 \%-50 \%$ of women suffering from endometriosis are infertile [32], its treatment constitutes a large part of the disease management plan. Previous work has established that the effectiveness of fertility treatment is inversely proportional to the severity of disease and that fertility outcomes in response to treatment are better in women with milder forms of endometriosis [72, 73]. This is probably due to poor ovarian reserve and oocyte quality and lower rates of implantation in women with stage III-IV endometriosis. Thus, the use of expectant management is an option only for women with less severe forms of endometriosis, and even then, guidelines recommend the use of controlled ovarian stimulation along with intra-uterine insemination for the improvement of fertility outcomes. However, those with infertility and advanced stage disease must receive effective treatment in order to improve fecundity. In general, medically assisted reproduction techniques such as ovulation induction and stimulation, intrauterine insemination and other assisted reproduction techniques such as in-vitro fertilization (IVF) are recommended by most international guidelines including the CMA for the treatment of endometriosis associated infertility. In general, IVF is known to be highly effective in such cases and a meta-analysis by Barnhart et al., showed that the presence of endometriosis affected the fertility outcomes in patients receiving IVF only in cases of severe disease [74].

While medical treatments such as NSAIDS, oral contraceptives, progestins, and $\mathrm{GnRH}$ analogues are useful for the management of endometrial symptoms such as dyspareunia and dysmenorrhea, recent literature provides no evidence of their effectiveness for treating endometriosis related infertility in patients who desire a live birth. However, both GnRHa and oral contraceptives have been shown to improve outcomes in patients using IVF and assisted reproduction techniques [75].

Surgical treatment of endometriosis is an option for cases where mild to moderate disease is present as well as in cases where severe disease is detected along with poor fertility outcomes. However, the goal of surgery in these cases is to limit the extent of ovarian resection. Cumulative evidence has shown that laparoscopic surgery (by excision as well as ablation) is highly effective and significantly improves fertility outcomes in patients with minimal to moderate endometriosis already using Medically Assisted Reproduction (MAR) [76]. However, although evidence for its use in combination with other MAR techniques in severe cases is lacking; an individualized decision based on specific patient characteristics is recommended by all guidelines.

Fertility outcomes using combinatorial therapy were also evaluated in a retrospective study of 138 Chinese women. The authors concluded that GnRH agonists combined with the transvaginal ultrasound-guided cyst aspiration procedure results in improved therapeutic effects and pregnancy outcomes in infertile patients with ovarian endometriosis who underwent IVF-ET [77]. This represents a significant advancement, since the use of transvaginal ultrasound-guided cyst aspiration alone has been found to result in a very high rate of disease recurrence [78]. However, since these results are from a single 
study, current guidelines do not recommend this combination for the improvement of pregnancy outcomes. Another study in a group of 168 Chinese women with Stage III-IV endometriosis demonstrated that 2-month treatment with a GnRH agonist prior to IVF tended to increase the implantation rate, showing that the timing and duration of $\mathrm{GnRH}$ agonist therapy can also affect fertility outcomes [79]. However, current guidelines only recommend the use of $\mathrm{GnRH}$ agonists for the improvement of fertility outcomes in patients with severe disease (stage III-IV endometriosis based on rASRM classification) when used in combination with other surgical or MAR procedures [55].

It is believed that endometriosis occurs due to blood stasis which has manifested due to kidney Yang deficiency, liver Qi stagnation, or cold [80]. By targeting blood stasis, TCM aims to treat endometriosis and increase fertility. Indeed, a recent meta-analysis which compared TCM with WM found the former to improve pregnancy rates by almost 2-fold within 3-6 months of treatment initiation [80]. This mechanism treats endometriosis-related symptoms too. In endometriosis affected patients, the reduction in pain and adnexal mass with TCM was more than with danazol, but comparable with gestrinone. Compared with WM, a significant increase in pregnancy rate with TCM after laparoscopy (61.3\% vs $45.5 \%, P<0.05)$ [81], but not without $(52.5 \%$ vs $37.5 \%, P=0.265)$ was reported [82]. However, both the studies reported that TCM increases negative conversion of endometrial antibody significantly.

\section{Evaluation of HRQoL and clinical guidelines for the management of Chinese women with endometriosis}

Since women with endometriosis are known to suffer from a significant deterioration in quality of life and fertility outcomes, HRQoL assessment is important during the clinical evaluation of treatment efficacy in endometriosis patients. Although generic Visual Analog Scales such as Short-Form 36 or Short-Form 12 and EuroQoL may be used to evaluate the efficacy of treatments in terms of HRQoL, several specific questionnaires that focus on different endometriosis-related QoL parameters such as self-image, relationship with children, effect on work life, and productivity have been developed. For example, the Endometriosis Health Profile-30 questionnaire which has been translated into Chinese [83, 84] and the much shorter Endometriosis Health Profile-5 questionnaire are commonly used for such assessments. In a study of 336 Chinese women, the authors found that the translated Endometriosis Health Profile-30 questionnaire was internally consistent and valid for use as an effective scale for the assessment of HRQoL in Chinese women [83].
Several international societies and organizations exist that regularly publish guidelines and updates for the management of endometriosis in patients. Among these, guidelines by the International Society for Gynecologic Endoscopy, the American Association of Gynecologic Laparoscopists, the European Society for Gynecological Endoscopy and the Australian Gynecological Endoscopy and Surgical Society are widely consulted. The ESHRE guidelines represent standardized clinical guidelines for the management of endometriosis worldwide $[45,55]$. In general, the recommendations of the CMA are in line with international guidelines and discuss and propose different patient management strategies, as summarized in the above sections of this article.

Recently, the WES derived a set of consensus guidelines for the management of patients with endometriosis. This consensus statement was drafted after consultation with an international panel of experts and is the first guideline that represents the views of women affected by endometriosis themselves [85]. Of particular interest is the fact that these guidelines address the issue of patient management in under-studied groups such as adolescents and post-menopausal women. They also propose models for the management of disease in low resource settings, which is a significant concern in large and developing economies like China.

\section{Conclusions}

In conclusion, although WM has been studied and validated more extensively for the treatment of endometriosis, TCM and WM are both used equally in the treatment of endometriosis in Chinese women. In addition, although guidelines recommend the use of different disease management strategies based on the extent and severity of endometrial lesions, long-term medical management is highly recommended in order to prevent exacerbation and recurrence. Guidelines by the CMA are aligned with those by the WES and ESHRE and in general, medical management is recommended over surgical treatment. More research is required on non-invasive diagnostic methods in order to accurately detect the presence of disease before a laparoscopy and to enable individualized treatment of patients while improving patient outcomes. While extensive studies have been conducted on the genetic basis of endometriosis in the female Chinese population, a clear association between the presence of mutations and polymorphisms and the clinical manifestation of disease has not been made. In addition, data regarding the underlying mechanisms involved are also limited and an extensive study of these factors is likely to allow clinicians to better manage the affected population. 


\section{Abbreviations}

CMA: Chinese Medical Association; EFI: Endometriosis Fertility Index ESHRE: European Society of Human Reproduction and Embryology; GnRHa: Gonadotropin-releasing hormone agonist; HRQoL: Health Related Quality of Life; IVF: In-vitro fertilization; LNG-IUS: Levonorgestrel intrauterine system; MAR: Medically assisted reproduction; QOL: Quality of life; rASRM: American Society of Reproductive Medicine; SNP: Single nucleotide polymorphisms; TCM: Traditional Chinese medicine; WES: World Endometriosis Society; WM: Western Medicine

\section{Acknowledgements}

The authors acknowledge Dr. Kripa Madnani (PhD), Leo J. Philip Tharappel, and Dr. Amit Bhat (PhD) from Indegene Pvt. Ltd. for their medical writing assistance and critical evaluation of the supporting literature (funded by Bayer AG) while drafting this review article.

\section{Availability of data and materials}

Data sharing not applicable to this article as no datasets were generated or analyzed during the current work.

\section{Authors' contributions}

All authors have contributed equally in the development of this manuscript All authors read and approved the final manuscript.

\section{Ethics approval and consent to participate}

Not applicable.

\section{Competing interests}

The authors declare that they have no competing interests.

\section{Publisher's Note}

Springer Nature remains neutral with regard to jurisdictional claims in published maps and institutional affiliations.

\section{Received: 24 October 2017 Accepted: 11 April 2018}

\section{Published online: 21 May 2018}

\section{References}

1. Vercellini P, Vigano P, Somigliana E, Fedele L. Endometriosis: pathogenesis and treatment. Nat Rev Endocrinol. 2014;10:261-75.

2. Giudice LC, Kao LC. Endometriosis. Lancet. 2004;364:1789-99.

3. Eisenberg VH, Weil C, Chodick G, Shalev V. Epidemiology of endometriosis: a large population-based database study from a healthcare provider with 2 million members. BJOG. 2018;125:55-62.

4. Han XT, Guo HY, Kong DL, Han JS, Zhang LF. Analysis of characteristics and influence factors of diagnostic delay of endometriosis. Zhonghua Fu Chan Ke Za Zhi. 2018:53:92-98.

5. Arumugam K, Templeton AA. Endometriosis and race. Aust N Z J Obstet Gynaecol. 1992;32:164-5.

6. Hasson HM. Incidence of endometriosis in diagnostic laparoscopy. J Reprod Med. 1976;16:135-8.

7. Sangi-Haghpeykar H, Poindexter A III. Epidemiology of endometriosis among parous women. Obstet Gynecol. 1995;85:983-92.

8. Wu Z, Yuan M, Li Y, Fu F, Ma W, Li H, et al. Analysis of WNT4 polymorphism in Chinese Han women with endometriosis. Reprod BioMed Online. 2015; 30:415-20.

9. Chen XP, Xu DF, Xu WH, Yao J, Fu SM. Glutathione-S-transferases M1/T1 gene polymorphisms and endometriosis: a meta-analysis in Chinese populations. Gynecol Endocrinol. 2015;31:840-5.

10. Fan W, Huang Z, Xiao Z, Li S, Ma Q. The cytochrome P4501A1 gene polymorphisms and endometriosis: a meta-analysis. J Assist Reprod Genet. 2016;33:1373-83.

11. Yang CW, Chang CYY, Lai MT, Chang HW, Lu CC, Chen Y, et al. Genetic variations of MUC17 are associated with endometriosis development and related infertility. BMC Med Genet. 2015:16:60.

12. Buck Louis GM, Peterson CM, Chen Z, Croughan M, Sundaram R, Stanford J, et al. Bisphenol a and phthalates and endometriosis: the endometriosis: natural history, diagnosis and outcomes study. Fertil Steril. 2013;100:162-9.

13. Louis GMB, Peterson CM, Chen Z, Hediger ML, Croughan MS, Sundaram R, et al. Perfluorochemicals and endometriosis. Epidemiology. 2012;23:799-805.
14. Louis GMB, Chen Z, Peterson CM, Hediger ML, Croughan MS, Sundaram R et al. Persistent lipophilic environmental chemicals and endometriosis: the ENDO study. Environ Health Perspect. 2012;120:811-6.

15. Kim SH, Chun S, Jang JY, Chae HD, Kim CH, Kang BM. Increased plasma levels of phthalate esters in women with advanced-stage endometriosis: a prospective case-control study. Fertil Steril. 2011;95:357-9.

16. Missmer SA, Hankinson SE, Spiegelman D, Barbieri RL, Michels KB, Hunter DJ. In utero exposures and the incidence of endometriosis. Fertil Steril. 2004;82:1501-8

17. Lin WC, Chang CYY, Hsu YA, Chiang JH, Wan L. Increased risk of endometriosis in patients with lower genital tract infection. Medicine (Baltimore). 2016;95:e2773.

18. Frisch SM, Francis $\mathrm{H}$. Disruption of epithelial cell-matrix interactions induces apoptosis. J Cell Biol. 1994;124:619-26.

19. Sampson JA. Peritoneal endometriosis due to the menstrual dissemination of endometrial tissue into the peritoneal cavity. Am J Obstet Gynecol. 1927; 14:422-69.

20. Jin A, Chen H, Wang C, Tsang LL, Jiang X, Cai Z, et al. Elevated expression of CD147 in patients with endometriosis and its role in regulating apoptosis and migration of human endometrial cells. Fertil Steril. 2014;101:1681-7. e1

21. Tian X, Xu L, Wang P. MiR-191 inhibits TNF-a induced apoptosis of ovarian endometriosis and endometrioid carcinoma cells by targeting DAPK1. Int J Clin Exp Pathol. 2015:8:4933-42.

22. Zhao L, Yang H, Xuan Y, Luo Z, Lin Q, Zhao J, et al. Increased expression of fibroblast growth factor receptor 1 in endometriosis and its correlation with endometriosis-related dysmenorrhea and recurrence. Eur J Obstet Gynecol Reprod Biol. 2015;184:117-24.

23. Dong M, Yang P, Hua F. miR-191 modulates malignant transformation of endometriosis through regulating TIMP3. Med Sci Monit. 2015;21:915-20.

24. Burney RO, Giudice LC. Pathogenesis and pathophysiology of endometriosis. Fetil Steril. 2012;98:511-9.

25. Hufnagel D, Li F, Cosar E, Krikun G, Taylor HS. The role of stem cells in the etiology and pathophysiology of endometriosis. Semin Reprod Med. 2015 33:333-40.

26. Cheng $\mathrm{CH}$, Kuo HC, Su B. Endometriosis in a kidney with focal xanthogranulomatous pyelonephritis and a perinephric abscess. BMC Res Notes. 2015:8:591.

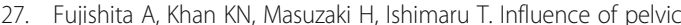
endometriosis and ovarian Endometrioma on fertility. Gynecol Obstet Investig. 2002:53(Suppl. 1):40-5.

28. Adamson GD, Pasta DJ. Endometriosis fertility index: the new, validated endometriosis staging system. Fertil Steril. 2010;94:1609-15.

29. Cooperative Group of Endometriosis, Chinese Society of Obstetrics and Gynecology, Chinese Medical Association. Guideline for the diagnosis and treatment of endometriosis. Zhonghua Fu Chan Ke Za Zhi. 2015;50:161-9.

30. Wee-Stekly WW, Kew CCY, Chern BSM. Endometriosis: a review of the diagnosis and pain management. Gynecol Minim Invasive Ther. 2015:4 106-9.

31. Facchin F, Barbara G, Saita E, Mosconi P, Roberto A, Fedele L, et al. Impact of endometriosis on quality of life and mental health: pelvic pain makes the difference. J Psychosom Obstet Gynecol. 2015:36:135-41.

32. Verkauf BS. Incidence, symptoms, and signs of endometriosis in fertile and infertile women. J Fla Med Assoc. 1987:74:671-5.

33. Zullo F, Spagnolo E, Saccone G, Acunzo M, Xodo S, Ceccaroni M, et al. Endometriosis and obstetrics complications: a systematic review and metaanalysis. Fertil Steril. 2017;108:667-72. e5

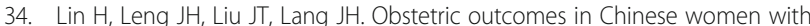
endometriosis: a retrospective cohort study. Chin Med J. 2015;128:455.

35. Kim HS, Kim TH, Chung HH, Song YS. Risk and prognosis of ovarian cancer in women with endometriosis: a meta-analysis. Br J Cancer. 2014;110:1878-90.

36. Pearce $\mathrm{CL}$, Templeman $\mathrm{C}$, Rossing MA, Lee A, Near AM, Webb PM, et al. Association between endometriosis and risk of histological subtypes of ovarian cancer: a pooled analysis of case-control studies. Lancet Oncol. 2012;13:385-94

37. Zafrakas M, Grimbizis G, Timologou A, Tarlatzis BC. Endometriosis and ovarian Cancer risk: a systematic review of epidemiological studies. Front Surg. 2014;1:14.

38. Ye S, Yang J, You Y, Cao D, Bai H, Lang J, et al. Comparative study of ovarian clear cell carcinoma with and without endometriosis in People's republic of China. Fertil Steril. 2014;102:1656-62. 
39. Buck Louis GM, Hediger ML, Peterson CM, Croughan M, Sundaram R, Stanford J, et al. Incidence of endometriosis by study population and diagnostic method: the ENDO study. Fertil Steril. 2011;96:360-5.

40. Soliman AM, Yang H, Du EX, Kelley C, Winkel C. The direct and indirect costs associated with endometriosis: a systematic literature review. Hum Reprod. 2016;31:712-22.

41. Wang HS, Wu HM, Cheng BH, Yen CF, Chang PY, Chao A, et al. Functional analyses of endometriosis-related polymorphisms in the estrogen synthesis and metabolism-related genes. PLoS One. 2012;7:e47374.

42. Li X, Zhang Y, Zhao L, Wang L, Wu Z, Mei Q, et al. Whole-exome sequencing of endometriosis identifies frequent alterations in genes involved in cell adhesion and chromatin-remodeling complexes. Hum Mol Genet. 2014;23:6008-21.

43. Li Y, Hao N, Wang Y, Kang S. Association of endometriosis-associated genetic polymorphisms from genome-wide association studies with ovarian endometriosis in a Chinese population. Reprod Sci. 2017;24:109-13.

44. Nyholt DR, Low S-K, Anderson CA, Painter JN, Uno S, Morris AP, et al. Genome-wide association meta-analysis identifies new endometriosis risk loci. Nat Genet. 2012;44:1355-9.

45. Dunselman GAJ, Vermeulen N, Becker C, Calhaz-Jorge C, D'Hooghe T, De Bie $B$, et al. ESHRE guideline: management of women with endometriosis. Hum Reprod. 2014;29:400-12.

46. Shen A, Xu S, Ma Y, Guo H, Li C, Yang C, et al. Diagnostic value of serum CA125, CA19-9 and CA15-3 in endometriosis: a meta-analysis. J Int Med Res. 2015:43:599-609.

47. Yang $H$, Zhu L, Wang S, Lang J, Xu T. Noninvasive diagnosis of moderate to severe endometriosis: the platelet-lymphocyte ratio cannot be a neoadjuvant biomarker for serum Cancer antigen 125. J Minim Invasive Gynecol. 2015;22:373-7.

48. Asher V, Hammond R, Duncan TJ. Pelvic mass associated with raised CA 125 for benign condition: a case report. World J Surg Oncol. 2010;8:28.

49. Niloff JM, Klug TL, Schaetzl E, Zurawski VR, Knapp RC, Bast RC. Elevation of serum CA125 in carcinomas of the fallopian tube, endometrium, and endocervix. Am J Obstet Gynecol. 1984;148:1057-8.

50. Borrelli GM, Abrao MS, Mechsner S. Can chemokines be used as biomarkers for endometriosis? A systematic review. Hum Reprod. 2014;29:253-66.

51. Vodolazkaia A, El-Aalamat Y, Popovic D, Mihalyi A, Bossuyt X, Kyama CM, et al. Evaluation of a panel of 28 biomarkers for the non-invasive diagnosis of endometriosis. Hum Reprod. 2012;27:2698-711.

52. Wang L, Liu HY, Shi HH, Lang JH, Sun W. Urine peptide patterns for noninvasive diagnosis of endometriosis: a preliminary prospective study. Eur J Obstet Gynecol Reprod Biol. 2014;177:23-8.

53. Gupta D, Hull ML, Fraser I, Miller L, Bossuyt PM, Johnson N, et al. Endometrial biomarkers for the non-invasive diagnosis of endometriosis. Cochrane Database Syst Rev. 2016:4:CD012165.

54. Nisenblat V, Bossuyt PM, Shaikh R, Farquhar C, Jordan V, Scheffers CS, et al. Blood biomarkers for the non-invasive diagnosis of endometriosis. Cochrane Database Syst Rev. 2016;5:CD012179.

55. Kennedy S, Bergqvist A, Chapron C, D'Hooghe T, Dunselman G, Greb R, et al. ESHRE guideline for the diagnosis and treatment of endometriosis. Hum Reprod. 2005;20:2698-704.

56. Somigliana E, Vercellini P, Vigano P, Benaglia L, Busnelli A, Fedele L. Postoperative medical therapy after surgical treatment of endometriosis: from adjuvant therapy to tertiary prevention. J Minim Invasive Gynecol. 2014;21:328-34.

57. Wu L, Wu Q, Liu L. Oral contraceptive pills for endometriosis after conservative surgery: a systematic review and meta-analysis. Gynecol Endocrinol. 2013;29:883-90.

58. Li Z, Zhang HY, Zhu YJ, Hu YJ, Qu PP. A randomized study comparing the side effects and hormonal status of triptorelin and leuprorelin following conservative laparoscopic surgery for ovarian endometriosis in Chinese women. Eur J Obstet Gynecol Reprod Biol. 2014;183:164-8.

59. Gong L, Zhang S, Han Y, Long Q, Zou S, Cao Y. Initiation of GnRH agonist treatment on 3-5 days postoperatively in endometriosis patients: a randomized controlled trial. J Clin Pharmacol. 2015:55:848-53.

60. Liu C, Lu Q, Zhang Z, Xue M, Zhang Y, Zhang Y, et al. A randomized controlled trial on the efficacy and safety of a new crosslinked hyaluronan gel in reducing adhesions after gynecologic laparoscopic surgeries. J Minim Invasive Gynecol. 2015;22:853-63.

61. Gerlinger C, Faustmann T, Hassall JJ, Seitz C. Treatment of endometriosis in different ethnic populations: a meta-analysis of two clinical trials. BMC Womens Health. 2012;12:9.

62. Maxwell GL, Tian C, Risinger Jl, Hamilton CA, Barakat RR, Gynecologic Oncology Group Study. Racial disparities in recurrence among patients with early-stage endometrial cancer: is recurrence increased in black patinets who receive estrogen replacement therapy? Cancer. 2008;113:1431-7.

63. Maxwell GL, Shoji Y, Darcy K, Litzi T, Berchuck A, Hamilton CA, et al. MicroRNAs in endometrial cancers from black and white patients. Am J Obstet Gynecol. 2015;212:191. e1-10

64. Cote ML, Atikukke G, Ruterbusch JJ, Olson SH, Sealy-Jefferson S, Rybicki BA, et al. Racial differences in oncogene mutations detected in early-stage lowgrade endometrial cancers. Int H Gynecol Cancer. 2012;22:1367-72.

65. Zhao L, Wu H, Zhou X, Wang Q, Zhu W, Chen J. Effects of progressive muscular relaxation training on anxiety, depression and quality of life of endometriosis patients under gonadotrophin-releasing hormone agonist therapy. Eur J Obstet Gynecol Reprod Biol. 2012;162:211-5.

66. Flower A, Liu JP, Lewith G, Little P, Li Q. Chinese herbal medicine for endometriosis. Cochrane Database Syst Rev. 2012;(5):CD006568.

67. Zhu S, Liu D, Huang W, Wang Q, Wang Q, Zhou L, et al. Post-laparoscopic oral contraceptive combined with Chinese herbal mixture in treatment of infertility and pain associated with minimal or mild endometriosis: a randomized controlled trial. BMC Complement Altern Med. 2014;14:222.

68. Su SY, Muo CH, Sung FC, Morisky DE. Reduction of surgery rate in endometriosis patients who take Chinese medicine: a population-based retrospective cohort study. Complement Ther Med. 2014;22:632-9.

69. Zhao R, Hao Z, Zhang Y, Lian F, Sun W, Liu Y, et al. Controlling the recurrence of pelvic endometriosis after a conservative operation: comparison between Chinese herbal medicine and western medicine. Chin J Integr Med. 2013;19:820-5.

70. Zhao R, Liu Y, Tan Y, Hao Z, Meng Q, Wang R, et al. Chinese medicine improves postoperative quality of life in endometriosis patients: a randomized controlled trial. Chin J Integr Med. 2013;19:15-21.

71. Flower A, Lewith GT, Little P. Seeking an Oracle: using the Delphi process to develop practice guidelines for the treatment of endometriosis with Chinese herbal medicine. J Altern Complement Med. 2007;13:969-76.

72. Nezhat C. Endometriosis : advanced management and surgical techniques. New York: Springer-Verlag; 1995.

73. Jarrett JC, Rausch DT. The fertility guide : a couples handbook for informed, rational, and effective fertility treatment. Santa Fe: Health Press; 1998.

74. Barnhart K, Dunsmoor-Su R, Coutifaris C. Effect of endometriosis on in vitro fertilization. Fertil Steril. 2002;77:1148-55.

75. Sallam HN, Garcia-Velasco JA, Dias S, Arici A, Abou-Setta AM. Long-term pituitary down-regulation before in vitro fertilization (IVF) for women with endometriosis. Cochrane Database Syst Rev. 2006;1:CD004635.

76. Jacobson TZ, Duffy JM, Barlow DH, Farquhar C, Koninckx PR, Olive D. Laparoscopic surgery for subfertility associated with endometriosis. In: Jacobson TZ, editor. Cochrane database of systematic reviews. Chichester, UK: John Wiley \& Sons, Ltd; 2010. p. CD001398.

77. Guo Y, Lu N, Zhang Y, Su Y, Wang Y, Zhang Y, et al. Comparative study on the pregnancy outcomes of in vitro fertilization-embryo transfer between long-acting gonadotropin-releasing hormone agonist combined with transvaginal ultrasound-guided cyst aspiration and long-acting gonadotropin-releasing hormone agonist alone. Contemp Clin Trials. 2012; 33:1206-10

78. Chan LY, So WW, Lao TT. Rapid recurrence of endometrioma after transvaginal ultrasound-guided aspiration. Eur J Obstet Gynecol Reprod Biol. 2003;109:196-8.

79. Ma C, Qiao J, Liu P, Chen G. Ovarian suppression treatment prior to in-vitro fertilization and embryo transfer in Chinese women with stage III or IV endometriosis. Int J Gynecol Obstet. 2008;100:167-70.

80. Ried K. Chinese herbal medicine for female infertility: an updated metaanalysis. Complement Ther Med. 2015;23:116-28.

81. Qi YH, Lian F. Clinical study on treatment of endometriosis-related infertility patients by laparoscopic surgery in combination of quyu jiedu recipe. Zhongguo Zhong Xi Yi Jie He Za Zhi. 2011;31:892-5.

82. Ding Z, Lian F. Traditional Chinese medical herbs staged therapy in infertile women with endometriosis: a clinical study. Int J Clin Exp Med. 2015;8:14085-9.

83. Jia SZ, Leng JH, Sun PR, Lang JH. Translation and psychometric evaluation of the simplified Chinese-version endometriosis health Profile-30. Hum Reprod. 2013;28:691-7.

84. Jones G, Kennedy S, Barnard A, Wong J, Jenkinson C. Development of an endometriosis quality-of-life instrument: the endometriosis health Profile-30. Obstet Gynecol. 2001;98:258-64.

85. Johnson NP, Hummelshoj L, Abrao MS, Adamson GD, Allaire C, Amelung V, et al. Consensus on current management of endometriosis. Hum Reprod. 2013;28:1552-68. 
86. Wang W, Li Y, Maitituoheti M, Yang R, Wu Z, Wang T, et al. Association of an oestrogen receptor gene polymorphism in Chinese Han women with endometriosis and endometriosis-related infertility. Reprod BioMed Online. 2013;26:93-8.

87. Guo R, Zheng N, Ding S, Zheng Y, Feng L. Associations between estrogen receptor-beta polymorphisms and endometriosis risk: a meta-analysis. Diagn Pathol. 2014;9:184

88. Mao T, Luo X, Tan X, Jiang X, Wang Y, Huang $Y$, et al. Association of the $\mathrm{H} 770 \mathrm{H}$ of PR gene polymorphism with susceptibility to endometriosis. Zhonghua Fu Chan Ke Za Zhi. 2015;50:194-7.

89. Zhu H, Bao J, Liu S, Chen Q, Shen H. Null genotypes of GSTM1 and GSTT1 and endometriosis risk: a meta-analysis of 25 case-control studies. PLoS One. 2014;9:e106761.

90. He C, Song Y, He X, Zhang W, Liao L. No association of endometriosis with galactose-1-phosphate uridyl transferase mutations in a Chinese population. Environ Mol Mutagen. 2006:47:307-9.

91. Zhang QY, Guan Q, Wang Y, Feng X, Sun W, Kong FY, et al. BDNF Val66Met polymorphism is associated with stage III-IV endometriosis and poor in vitro fertilization outcome. Hum Reprod. 2012;27:1668-75.

92. Kang S, Li SZ, Wang N, Zhou RM, Wang T, Wang DJ, et al. Association between genetic polymorphisms in fibroblast growth factor (FGF)1 and FGF2 and risk of endometriosis and adenomyosis in Chinese women. Hum Reprod. 2010;25:1806-11.

93. Fang $F$, Gong L, Wang X, Zhang L. The association between vascular endothelial growth factor ( VEGF ) +405G\&gt;C genetic polymorphism and endometriosis. Exp Biol Med. 2015;240:1177-82.

94. Liu Q, Li Y, Zhao J, Sun DL, Duan YN, Wang N, et al. Association of polymorphisms -1154G/a and -2578C/a in the vascular endothelial growth factor gene with decreased risk of endometriosis in Chinese women. Hum Reprod. 2009;24:2660-6.

95. Kang S, Shi Y, Li Y, Wang N, Lu Y, Zhou R, et al. Association between genetic variants of the VEGFR-2 gene and the risk of developing endometriosis in northern Chinese women. Gynecol Obstet Investig. 2013;76:32-7.

96. Chang CC, Hsieh YY, Tsai FJ, Tsai CH, Der Tsai H, Lin CC. The proline form of p53 codon 72 polymorphism is associated with endometriosis. Fertil Steril. 2002;77:43-5.

97. Jia S, Xu L, Chan Y, Wu X, Yang S, Yu H, et al. p53 codon 72 polymorphism and endometriosis: a meta-analysis. Arch Gynecol Obstet. 2012;285:1657-61.

98. Kang S, Zhao XW, Wang N, Chen SC, Zhou RM, Li Y. Association of polymorphisms of the MMP-2 and TIMP-2 genes with the risk of endometriosis in north Chinese women. Fertil Steril. 2008;90:2023-9.

99. Kang S, Li Y, Li B, Wang N, Zhou R-M, Zhao X. Genetic variation of the Ecadherin gene is associated with primary infertility in patients with ovarian endometriosis. Fertil Steril. 2014;102:1149-54. e1

100. Wang Y, Qu Y, Song W. Genetic variation in COX-2 -1195 and the risk of endometriosis and adenomyosis. Clin Exp Obstet Gynecol. 2015;42:168-72.

101. Pabalan N, Jarjanazi H, Christofolini DM, Barbosa CP, Bianco B. Association of the intercellular adhesion molecule-1 (ICAM-1) gene polymorphisms with endometriosis: a systematic review and meta-analysis. Arch Gynecol Obstet. 2015;292:843-51.

102. Wang L, Lu X, Wang D, Qu W, Li W, Xu X, et al. CYP19 gene variant confers susceptibility to endometriosis-associated infertility in Chinese women. Exp Mol Med. 2014;46:e103.

103. Zhang H, Zhang Z, Li G, Wang S, Zhang S, Xie B. Association of FCRL3 genetic polymorphisms with endometriosis-related infertility risk. Medicine (Baltimore). 2015;94:e1168.

104. Gan XL, Lin YH, Zhang Y, Yu TH, Hu LN. Association of an Interleukin-16 gene polymorphism with the risk and pain phenotype of endometriosis. DNA Cell Biol. 2010;29:663-7.

105. Wang H-S, Cheng B-H, Wu H-M, Yen C-F, Liu C-T, Chao A, et al. A mutant single nucleotide polymorphism of follicle-stimulating hormone receptor is associated with a lower risk of endometriosis. Fertil Steril. 2011;95:455-7.

106. Hsieh YY, Bau DT, Chang CC, Tsai CH, Chen CP, Tsai FJ. XRCC4 codon 247*a and XRCC4 promoter $-1394 *$ T related genotypes but not XRCC4 intron 3 gene polymorphism are associated with higher susceptibility for endometriosis. Mol Reprod Dev. 2008;75:946-51.

107. Wu Z, Wang W, Wang T, Yang R, Li Y, Li T, et al. Association of FOXP3 gene polymorphism in Chinese women with endometriosis. Zhonghua Yi Xue Yi Chuan Xue Za Zhi. 2013;30:106-10.

\section{Ready to submit your research? Choose BMC and benefit from:}

- fast, convenient online submission

- thorough peer review by experienced researchers in your field

- rapid publication on acceptance

- support for research data, including large and complex data types

- gold Open Access which fosters wider collaboration and increased citations

- maximum visibility for your research: over $100 \mathrm{M}$ website views per year

At BMC, research is always in progress.

Learn more biomedcentral.com/submissions 